\title{
A COMPREHENSIVE UPDATE ON INCIDENCE, PREVALENCE AND COMPLEX ETIOLOGY OF CENTRAL LINE-ASSOCIATED BLOOD- STREAM INFECTION IN PEDIATRIC INTENSIVE CARE UNITS IN KING SAUD MEDICAL CITY
}

\author{
Dr Juhaina Abdulrahiem ${ }^{1}$, Asia Sultan Sultan ${ }^{1}$, Faisl Alaklobi ${ }^{1}$, Hala Amer ${ }^{1}$ and Hind \\ Alzoman $^{1}$ \\ ${ }^{1}$ Infection control department, King Saud Medical City Riyadh, Saudi Arabia
}
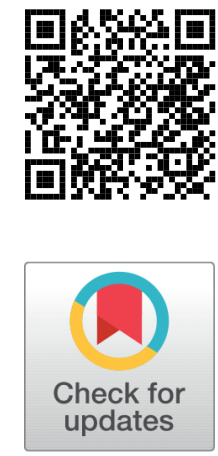

Received 20 April 2021

Accepted 9 May 2021

Published 31 May 2021

Corresponding Author

Dr Juhaina Abdulrahiem, juhina16

@hotmail.com

DOI 10.29121/

granthaalayah.v9.i5.2021.3907

Funding: This research received no specific grant from any funding agency in the public, commercial, or not-for-profit sectors.

Copyright: (C) 2021 The Author(s). This is an open access article distributed under the terms of the Creative Commons Attribution License, which permits unrestricted use, distribution, and reproduction in any medium, provided the original author and source are credited.

\section{ABSTRACT}

Central Line Associated Bloodstream Infection (CLABSI) is a type of bloodstream infection that is caused by microorganisms after the insertion of central lines. Paediatric Intensive Care Units have been studied to conduct this research on CLABSI in children from 2 to 15 years old. Children have been divided in two age groups that are 2-5 and 5-15 years. The Royal Children's Hospital, Melbourne has been chosen as a sample of this besides other five hospitals of Australia. A total of 350 patients are studied in the course of this research and 216 among them were inserted with central lines. Bloodstream infection has been identified in 49 patients from these 216 patients and CLABSI occurred in $75.51 \%$ of them that is 37 patients. Associated microorganisms and other underlying diseases are listed in this study to develop an idea about factors responsible for CLABSI.

Keywords: Paediatric, Central Line Associated Bloodstream Infection, Etiology

\section{OBJECTIVE}

- Aim of this research is to give a brief insight about the incidence, prevalence and complexity of the CLABSI in Paediatric Intensive Care Units (PICU).

- To determine the prevalence of central line-associated bloodstream infections in the paediatric intensive care units

- To assess the complexity of central line-associated bloodstream infections (CLABSI) in hospitalized children

- To determine the types of bloodstream infection among the children admitted to paediatric intensive care units

- To determine the importance of central line-associated bloodstream infections from the epidemiological perspectives 


\section{RESEARCH QUESTION}

- What is the degree of prevalence of central line-associated bloodstream infections in the paediatric intensive care units?

- What are the complexities related to the CLABSI in case of children admitted to the paediatric intensive care units?

- What types of central line-associated bloodstream infections are observed among children admitted to the pediatric intensive care units?

- What is the epidemiological perspective of central line-associated bloodstream infections?

\section{DESIGN}

A prospective cohort study has been applied in this research to develop a clear insight about the risk factors and prevalence of Central Line Associated Bloodstream Infection (CLABSI). Related ethical considerations have been taken into account in order to complete this research with the personal data of the subjected population. In terms of ethical measures, the name of any subject and their addresses has not been disclosed at any times. Data Protection Act 2014 has been adhered to in this research on risk factors and prevalence of CLABSI DeMuro et al. (2012). The subject of research is chosen to the children admitted to the PICU for more than 48 hours and at the time of admission, they had no infection.

\section{SETTING}

This research is going to deepen the knowledge of the researcher and the audiences in terms of risk factors related to central line-associated bloodstream infections. Therefore, this research needs to be conducted to forecast its chances of causing an epidemic in the near future. Peripherally inserted central venous catheters are seen to be posing high risk of bloodstream infections Armignacco et al. (2015). Therefore, on completion of this research, alternative ways of administering food, antibiotics and chemotherapy can be decided on. Prevalence of the disease and related complexities and death rates are going to be studied in this research and therefore, awareness can be spread among the audience.

\section{PATIENTS}

research is chosen to the children admitted to the PICU in KING SAUD MEDICAL CITY for more than 48 hours and at the time of admission, they had no infection. been conducted with data from 2015 to 2019 and patients with visible signs of CLABSI after central line insertion have been considered. Blood samples from the peripheral veins and catheter tip of the patients have been collected. Moreover, blood has been taken from the catheter of the patients who had no chance of infection other than the cen- 
tral line Patel et al. (2017). Any significant growth of the bacterial or fungal cultures on the plate has been considered to be clinically positive symptoms of CLABSI.

\section{RESULTS}

This research is based on data about Central-Line Associated Bloodstream Infection (CLABSI) from 2015 to 2019. The research on prevalence of infection and risk factors of CLABSI has not been focused on any particular hospital. Conduction of this research has been done with 350 patients from paediatric intensive care units of different hospitals. In terms of male patients, there were 192 and the rest 158 patients were female. Among these 350 patients, 216 were inserted with the central line and 132 patients happened to male.

Triple lumen was inserted into 101 patients; 89 patients were treated with single lumen. PICC was placed in 21 patients and the remaining 5 of them were administered with umbilical catheters. Bloodstream infection was seen in 49 patients and 37 among them were diagnosed with CLABSI that is approximately $75.51 \%$. The rest 12 patients occupying $24.5 \%$ of the infected individuals were reported to have secondary bloodstream infection. Type of central line was not seen to be associated with the development of Central Line Associated Bloodstream Infection (CLABSI) Tang et al. (2015).

The age groups have been taken into account and are reported for the patients who have been placed with central lines. Most of them were less than two years old and the number consumed approximately 60\% (130 children). Two to five years old patients consumed approximately $15 \%$ that was 33 people and the rest were of five to fifteen years old. The prevalent disorders among the patients with central line were metabolic disorders, cardiopulmonary diseases, respiratory difficulties and renal issues Woods-Hill et al. (2020).

The change of central line was performed in the case of 80 patients and these patients were observed to be more susceptible to CLABSI. Change in triple lumen central lines have been associated more with the bloodstream infections in patients admitted to paediatric intensive care units Lee et al. (2020a). Majority of the patients were inserted with central lines in their femoral veins (148 patients). However, the others received their central lines in umbilical,

subclavian and brachial veins. It is to be mentioned that the insertion site of the central line has not been found to be associated with CLABSI Grigg et al. (2019). Besides, patients who used to receive parenteral nutrition or gastric acid blockers could not be determined to have any extra risk of developing CLABSI.

Central Line Associated Bloodstream Infection (CLABSI) is found to be dependent on the number of times the central line is accessed after its insertion. This event has been observed to be frequent in case of patients who have developed CLABSI Constantinescu et al. (2020). Mortality rate is higher in patients with bloodstream infection in comparison to the patients with central lines and no infection Dube et al. 
(2020). This is commented as 12 patients among 49 infected individuals died that accounts for $24.5 \%$. On the contrary, 53 patients among the rest of 301 individuals died and it consumed $17.6 \%$ of them.

\section{CONCLUSION}

It can be concluded from this proposal that CLABSI is a serious condition in the children admitted to the PICU. Nearly 30000 cases of death are reported around the world and more than $60 \%$ of these cases occur in PICU. The Royal Children's Hospital in Australia has been chosen for conducting this research on CLABSI. A study from 2015 to 2019 has been considered and the accumulated data shows that the main cause of infection is either the contaminated blood or the central line origin. Handling of the central line equipments and administration of drugs and food are responsible for this disease besides contamination with various microorganisms. The major part of the microorganism that is seen to cause CLABSI is the Acinetobacter baumannii.

Forty nine patients with central line inserted in the body were seen to have bloodstream infection and 35 among them had CLABSI. The type of central line was not observed to be associated with the development of CLABSI however; the site of insertion can be responsible. Majority of the central line were inserted in the femoral veins and underlying diseases such as gastrointestinal disease are related to the development of CLABSI. Detailed information regarding the dependent and independent factors is listed in this study besides limitations and future scopes of the research.

\section{DISCUSSION}

The research on risk factors and prevalence of infections in CLABSI has been conducted with data from various hospitals between 2015 and 2019. At the end of this study, it can be identified that the triple lumen central line is extensively used in patients admitted to the paediatric intensive care units. These central lines are inserted mostly in the femoral veins that are called the insertion site of the central lines Moss et al. (0505). However, these factors could not be found to have any significant association with the development of CLABSI. Besides that, patients with total parenteral nutrition (TPN) and gastric acid blockers are not considered to have any extra risk of experiencing bloodstream infections Holder et al. (2020).

The associated factors with the development of CLABSI are seen to be faulty insertion of the central lines to the patients of PICU. Maintenance of hygiene at the time of accessing the central line machinery is an important factor behind bloodstream infection Burke et al. (2020). Moreover, the number of times central lines have been accessed after initial insertion is a responsible factor for CLABSI development. Albumin level, co-morbidity, malignancy of diseases, neurological disorders, traumas and previous surgeries are related to the death cases of CLABSI Baer et al. (2020). Patients who were subject to changing of central lines and triple lumen central lines 
were seen to be more susceptible with the development of bloodstream infections. It can be commented from the results that the age group of two to five is most susceptible to the bloodstream infection after insertion of the central line.

Various bacterial and fungal agents have been identified in the course of this study that has been reported to cause CLABSI in children with central lines Dube et al. (2020). The identified gram positive and gram negative bacteria are Klebsiella pneumoniae, Staphylococcus spp.,

Enterococcus spp. and Acinetobacter baumannii. Besides these bacterial agents, Candida spp. is identified to be an integrated part of the central line associated bloodstream infection. Data obtained from the study of the hospitals show that A. baumannii is the most prevalent agent to cause CLABSI in patients admitted to PICU.

In order to isolate these bacterial and fungal agents, blood has been collected from peripheral veins, catheter tip and from inside the catheter. Peripheral veins and catheter tips have been subjected for the patients who had a chance of infection from outside sources than central lines Constantinescu et al. (2020). On the contrary, blood has been collected from the catheter from the patients that had no chance of infection from sources other than catheter origins. BACTEC 9050 is an automated device that has been appointed to identify and isolate the bacterial species from the blood samples. Besides, fungal agents have been identified by a germ tube test as this device is specifically designed for bacterial agents.

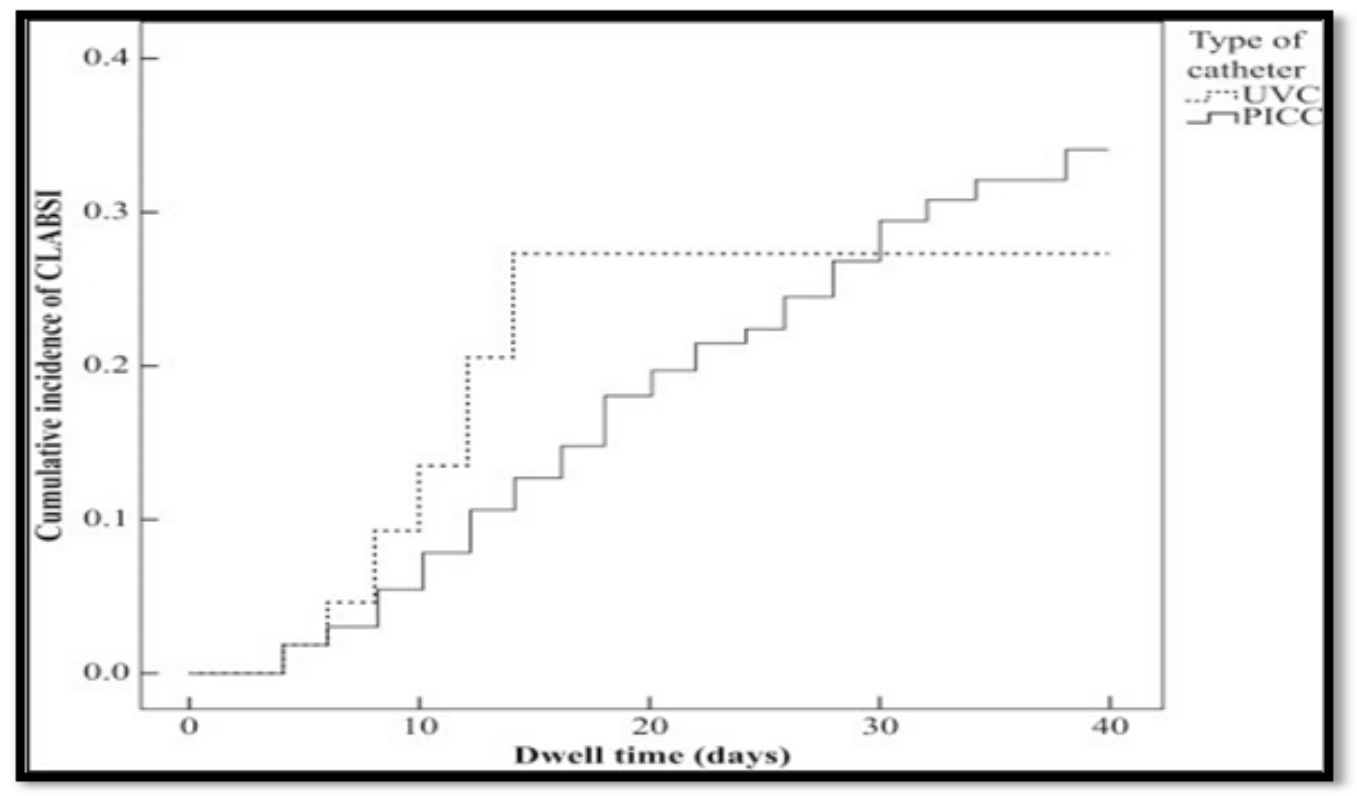

Figure 1 Dwell Time vs. Risk of Developing CLABSI

(Source: Rch.org.au, 2021) 


\section{ACKNOWLEDGMENTS}

For all health care workers are support our article study.

\section{REFERENCES}

Alghamdi, S. (2018). The Adoption of Antimicrobial Stewardship Programmes in Ministry of Health Hospitals in Saudi Arabia. University of Hertfordshire. https://doi.org/10 $.18745 /$ th. 21153

Almasadi, M. M., Al-Qahtani, S. M., \& Alhelali, I. (2020). Pattern and Frequency of Hospital Acquired Infections in Pediatric Intensive Care Unit at Abha Maternity and Children Hospital, Saudi Arabia. World Family Medicine Journal/Middle East Journal of Family Medicine, 18(8), 5-12. Retrieved from https://dx.doi.org/10.5742/mewfm.2020 .93839 10.5742/mewfm.2020.93839

Armignacco, P., Garzotto, F., Bellini, C., Neri, M., Lorenzin, A., Sartori, M., \& Ronco, C. (2015). Pumps in Wearable Ultrafiltration Devices: Pumps in Wuf Devices. Blood Purification, 39(1-3), 115-124. Retrieved from https://dx.doi.org/10.1159/000368943 10.1159/ 000368943

Ayaz, I., Hameed, H., Amber, W., \& Zafar, T. (2020). Nosocomial Blood Stream Infections in Pediatric Intensive Care Unit of Fauji Foundation Hospital, Rawalpindi Pakistan. Journal of Islamabad Medical \& Dental College, 9(4), 269-274. Retrieved from https://dx.doi .org/10.35787/jimdc.v9i4.533 10.35787/jimdc.v9i4.533

Baer, S. L., Larsh, A. H., Prunier, A., Thurmond, V., Goins, D., Hickox, N., Gardenhire, M., Walker, T., Bernal, S., Nowacki, M., Griffin, L., \& Hunter-Watson, H. (2020). Reduction of Central-Line-Associated Bloodstream Infections in a Spinal Cord Injury Unit (Vol. 41). Cambridge University Press (CUP). Retrieved from https://dx.doi.org/10.1017/ice .2020 .998 10.1017/ice.2020.998

Bearman, M., \& G. (2020). (Vol. 41). Cambridge University Press.

Burke, P., Nickoli, E., Sitaras, J., Mullins, W., \& Dandache, P. (2020). Peripherally Inserted Central Catheters Present on Admission and the Risk of Central-Line-Associated Bloodstream Infection (Vol. 41). Cambridge University Press (CUP). Retrieved from https:// dx.doi.org/10.1017/ice.2020.964 10.1017/ice.2020.964

catheter-associated urinary tract infection (CAUTI) in adult ICUs. (n.d.). Journal of hospital medicine, 13(2), 105-116.

Constantinescu, C., Furr, C. C., Vayalumkal, J., Conly, J., Gilfoyle, E., \& Kassam, A. (2020). Friend or Foe: Perceptions of Infectious Disease Specialists as Stewards and Social Determinants of Antimicrobial Prescribing (Vol. 41). Cambridge University Press (CUP). Retrieved from https://dx.doi.org/10.1017/ice.2020.791 10.1017/ice.2020.791

Coombs, G., Bell, J. M., Daley, D., Collignon, P., Cooley, L., Gottlieb, T., Iredell, J., Kotsanas, D., Nimmo, G., \& Robson, J. (2000). Level 5, 255 Elizabeth Street. Sydney NSW. Retrieved from Website:www.safetyandquality.gov.au

Costello, J. M., Morrow, D. F., Graham, D. A., Potter-Bynoe, G., Sandora, T. J., \& Laussen, P. C. (2008). Systematic Intervention to Reduce Central Line-Associated Bloodstream Infection Rates in a Pediatric Cardiac Intensive Care Unit. PEDIATRICS, 121(5), 915-923. Retrieved from https://dx.doi.org/10.1542/peds.2007-1577 10.1542/peds .2007-1577

DeMuro, J., McNelis, J., Hanna, A., Thekkel, V., Chandrankunnel, J., \& Cunha, B. A. (2012). Beyond Bundles and Coated Catheters: Effective Interventions to Decrease Central 
Line-Associated Bloodstream Infections (CLABSI) (Vol. 33). Cambridge University Press (CUP). Retrieved from https://dx.doi.org/10.1086/668035 10.1086/668035

Dube, W., Jacob, J., Zheng, Z., Huang, Y., Robichaux, C., Steinberg, J., \& Fridkin, S. (2020). The Second Central Line Increases Central-Line-Associated Bloodstream Infection Risk by 80\%: Implications for Inpatient Quality Reporting Programs, Infection Control \& Hospital Epidemiology. Cambridge University Press, 41(S1), 499-500. https://doi.org/ 10.1017/ice.2020.1180

Fakih, M. G., Groves, C., Bufalino, A., Sturm, L. K., \& Hendrich, A. L. (2017). Definitional Change in NHSN CAUTI Was Associated with an Increase in CLABSI Events: Evaluation of a Large Health System. Infection Control \& Hospital Epidemiology, 38(06), 685-689. Retrieved from https://dx.doi.org/10.1017/ice.2017.41 10.1017/ice.2017.41

Fontela, P. S., Rocher, I., Platt, R. W., Pai, M., Buckeridge, D. L., Frenette, C., Dionne, M., \& Quach, C. (2015). Evaluation of the Reporting Validity of Central Line-Associated Bloodstream Infection Data to a Provincial Surveillance Program. Cambridge University Press, 34(2). https://doi.org/10.1086/669074

Grigg, C., Nkwata, A., Gross, C., \& Magill, S. (2019). Characteristics of Pediatric Ventilator- Associated Events Reported to the National Healthcare Safety Network. Cambridge University Press, 41(S1), 164-164. https://doi.org/10.1017/ ice.2020.689[Opensinanewwindow]

Hammadi, A. A., Ostrosky-Zeichner, L., Boston, K., Mcinnis-Cole, T., \& Butler, J. (0113). Accuracy of the NHSN Central Line-Associated Bloodstream Infection (CLABSI) Definition. Open Forum Infectious Diseases, 5, 3-3.

Holder, C., Overton, E., Kalaf, S., Wong, D., Holdsworh, J., Yun, M., Schreck, D., Haun, P., Omess, S., Whitson, M., Ott, D., Mitchell, R., \& Steinberg, J. (2020). Impact of Expansion of Vascular Access Team on Central-line-Associated Bloodstream Infections. Infection Control \& Hospital Epidemiology, 41(S1), s260-s260. Retrieved from https://dx.doi .org/10.1017/ice.2020.825 10.1017/ice.2020.825

Infection Data to a Provincial Surveillance Program, Infection Control \& Hospital Epidemiology. (n.d.)., 34, 217-219.

Kendirli, T., Yaman, A., Ödek, Ç., Özdemir, H., Karbuz, A., Aldemir, B., Güriz, H., Ateș, C., Özsoy, G., Aysev, D., Çiftçi, E., \& İnce, E. (2017). Central Line-Associated Bloodstream Infections in Pediatric Intensive Care Unit. Turkish Journal of Pediatric Emergency and Intensive Care Medicine, 4(2), 42-46. Retrieved from https://dx.doi.org/10.4274/cayd 8658010.4274 /cayd. 86580

Lee, B., Durand, J., Jones, H., Gartner, N., Driscoll, J., Watson, C., Chandran, U., Sivarajan, V., Pereira, N., Clonfero, M., Degroot, J., \& Childs, M. (2020a). Collaborative.

Lee, B., Durand, J., Jones, H., Gartner, N., Driscoll, J., Watson, C., Chandran, U., Sivarajan, V., Pereira, N., Clonfero, M., Degroot, J., \& Childs, M. (2020b). Approach to Developing Infection Prevention Control Recommendations at a Tertiary-Care Pediatric Hospital, Infection Control \& Hospital Epidemiology. Cambridge University Press, 41(S1), 173-173. https://doi.org/10.1017/ice.2020.702[Opensinanewwindow]

Maria, G., \& Christos, T. (2020). The impact of central line insertion and maintenance care checklist on central line-associated bloodstream infections (CLABSIs): A literature review. Rostrum of Asclepius/Vima tou Asklipiou, 19(1).

Marschall, J., Mermel, L. A., Fakih, M., Hadaway, L., Kallen, A., Grady, N. P., Pettis, A. M., Rupp, M. E., Sandora, T., Maragakis, L. L., \& Yokoe, D. S. (2014). Strategies to Prevent Central Line-Associated Bloodstream Infections in Acute Care Hospitals. Infection Control \& Hospital Epidemiology, 35(S2), 89-107. 
Moss, M., Ehni, J., Herbison, I., Rabii, K. B., Koepsell, C., Devries, E., Fetman, R., Latrace, M., Mahoney, C. D., Neill, A., Kranitzky, B. ., Bailey, P. L., Patrick, A., Rittmann, B. J., Pryor, R., Cooper, K., \& Doll, M. E. (0505). Use of CLABSI Prevention Bundle Audits to Decrease CLABSI Rates in COVID Positive ICU Patients in an Acute Care Hospital in New York City During the COVID-19 Epidemic. In Open Forum Infectious Diseases (Vol. 7, pp. 318-319). Oxford University Press.

Niedner, M. F., Huskins, W. C., Colantuoni, E., Muschelli, J., Harris, J. M., Rice, T. B., Brilli, R. J., \& Miller, M. R. (2011). Epidemiology of Central Line-Associated Bloodstream Infections in the Pediatric Intensive Care Unit. Infection Control \& Hospital Epidemiology, 32(12), 1200-1208. Retrieved from https://dx.doi.org/10.1086/662621 10.1086/662621

Pan, R., Fuller, J., Gaines, T., Hill, J., Hueso, B., Liu, C., \& Mitchell, H. J. (2016).

Patel, P. K., Gupta, A., Vaughn, V. M., Mann, J. D., Ameling, J. M., \& Meddings, J. (2017). Review of strategies to reduce central line-associated bloodstream infection (CLABSI). Europe PMC, 105-116. Retrieved from https://europepmc.org/article/med/29154382 10 $.12788 /$ jhm.2856

Qiu, Y., Lam, J., Leung, S., \& Liang, W. (2016). Delivery of RNAi Therapeutics to the AirwaysFrom Bench to Bedside. Molecules, 21(9), 1249-1249. Retrieved from https://dx.doi .org/10.3390/molecules21091249 10.3390/molecules21091249

Rch, O., \& Au. (n.d.). 2021. About. Available.

Saedi, A., Jasthaniah, A., Yaseen, W., Alahmadi, M., Taguas, M., Tana, R., Abuskout, E., Younis, O., Daniel, O., Bhutta, M., Alshamrani, J., \& M. (2019). 34 Achieving and sustaining zero CLABSI events in oncology patients by implementing targeted interventions. BMJ Journal, 8. Retrieved from https://bmjopenquality.bmj.com/content/8/Suppl_1/A15.2

Steffens, R., \& Sarrazin, D. (2015).

Steiner-Dillon, J. (2019). Sticking Points: Epistemic Pluralism in Legal Challenges to Mandatory Vaccination Policies. SSRN Electronic Journal, 88, 169-169. Retrieved from https:// dx.doi.org/10.2139/ssrn.3334657 10.2139/ssrn.3334657

Tang, H. J., Lai, C. C., \& Chao, C. M. (2015). Central-Line-Associated Bloodstream Infection Caused by Sporobolomyces salmonicolor, Infection Control \& Hospital Epidemiology. Cambridge University Press, 36(9), 1111-1112. https://doi.org/10.1017/ice.2015.158

Weber, S., von Cube, M., Sommer, H., \& Wolkewitz, M. (2016). Necessity of a Competing Risk Approach in Risk Factor Analysis of Central Line-Associated Bloodstream Infection (Vol. 37). Cambridge University Press (CUP). Retrieved from https://dx.doi.org/ 10.1017/ice.2016.166 10.1017/ice.2016.166

White, J. T., \& Fraimow, H. (2011). Consistency versus Accuracy in Reporting Central Line-Associated Bloodstream Infections (Vol. 32). Cambridge University Press (CUP). Retrieved from https://dx.doi.org/10.1086/659955 10.1086/659955

Woods-Hill, C., Koontz, D., Voskertchian, A., Miller, M., Fackler, J., Shea, J., \& Milstone, M. (2020). Bright STAR Collaborative Consensus Guidelines for Blood Culture Use in Critically Ill Children, Infection Control \& Hospital Epidemiology. Cambridge University Press, 41(51), 22-23. https://doi.org/10.1017/ice.2020.499[Opensinanewwindow] 